\title{
Research and Application of Polycarboxylic Acid Water Reducer with Different Molecular Weight
}

\author{
Bobo Liu* Kangjian Yu* Yinggang Yang ${ }^{*}$ Donghui Miao* Chong $\mathrm{He}^{*}$ \\ KZJ New Materials Group Co., Ltd. Xian 710500, Shanxi, China
}

\begin{abstract}
In this paper, a polycarboxylic water reducing agent was synthesized by using Methylallyl polyethylene glycol (HPEG) with molecular weight of 1200, 2400, 2800 and 3400 under the same conditions, C80 concrete tests were performed on these four molecular weight superplasticizers, verify the effect of different molecular weight polycarboxylic acid water reducer in C80 pumping concrete, finally, a kind of low molecular weight polycarboxylic acid water reducer with viscosity reducing effect in high-grade concrete is obtained, which can promote pumping of high-grade concrete.
\end{abstract}

\section{Foreword}

As a third-generation concrete water reducer, polycarboxylic acid water reducer, due to its unique comb structure and steric hindrance effect, compared with naphthalene series water reducing agent, sulfonate series water reducing agent and fatty series water reducing agent, the performance of concrete mixture is significantly improved, therefore, it has been widely used at home and abroad in recent years. However, there are few researche on the special admixtures for high-grade concrete above C60 at home and abroad, in particular, high-grade pumping concrete is too viscous due to high glue and low water-to-binder ratio, the problem of high pumping pressure or even difficult pumping has not been solved. Most of the existing polycarboxylic acid water reducing agents are synthesized using 2400 molecular weight HPEG.The mother liquid has high water reducing rate, but its viscosity reducing effect is poor, which causes more problems in the application of high-grade concrete. He Tingshu, Li Guoxin and other professors from Xi'an University of Architecture and Technology have found that low molecular weight polycarboxylic acid water reducer disperses quickly in cement slurry due to its small molecular weight, and because its molecular weight is reduced, the steric hindrance effect of polycarboxylic acid water reducing agent is reduced and its sensitivity is reduced. Therefore, it has a better effect to high-grade concrete, which can effectively improve the difficulty to pump due to the high viscosity of high-grade concrete.

At present, there are few studies on the use of polycarboxylic acid water reducers with different molecular weights, and less mature products and synthetic processes. In particular, the research and application of low molecular weight polycarboxylic acid water reducers are insufficient. In this paper, polyether macromonomers of different molecular weights are selected, and a synthetic process is used to synthesize polycarboxylic acid water reducing agents of different molecular weights. The tests are performed in high-grade concrete to compare the viscosity-reducing effects of different molecular weight polycarboxylic acid water reducing agents. At the same time, a low molecular weight polycarboxylic acid water reducing agent with good viscosity reduction effect and its process are obtained.

\section{Test raw material}

\subsection{Chemical materials}

(1) Methylallyl polyethylene glycol (HPEG-M = 1200/2400/2800/3400): industrial product, produced in Wuhan;

(2) Mercaptoethanol: industrial product, produced in Guangdong;

(3) Acrylic acid (AA): analytical grade, produced by Sinopharm;

(4) Hydrogen peroxide (32\%, H2O2): analytical grade, produced by Sinopharm;

(5) Reducing agent $(\mathrm{F})$ : industrial product, made in Germany.

\subsection{Gelling material}

J Jidong P.O 52.5 cement; Weidian S1 fly ash.

\subsection{Aggregate}

river sand $(\mathrm{Mx}=2.3 \sim 3.0)$; double grade basalt, (small stone $5 \sim 16 \mathrm{~mm}$, large stone $5 \sim 31.5 \mathrm{~mm})$. 


\subsection{Polycarboxylic acid water reducer}

K PCE1 ( $\mathrm{M}=1200$ monomer synthesis), PCE2 ( $\mathrm{M}=$ 2400 monomer synthesis), PCE3 ( $\mathrm{M}=2800$ monomer synthesis), PCE4 (M = 3400 monomer synthesis); all four types of water reducing agent have solid contents $50 \%$.

\section{Experiment method}

\subsection{Synthesis and preparation of admixtures}

(1) Prepare liquid A and liquid B. Liquid A is composed of AA and part of deionized water; Liquid $\mathrm{B}$ is composed of $\mathrm{F}$, mercaptoethanol and deionized water;

(2) Add a certain amount of HPEG, hydrogen peroxide, and partially deionized water to a four-necked flask equipped with a thermometer and a stirrer, and stir to the state of an aqueous solution;

(3) Add A and B liquids at the same time. The addition of solution $\mathrm{A}$ was completed in $2 \mathrm{~h}$, and the addition of solution B was completed in $2.5 \mathrm{~h}$;

(4) Hold for half an hour, add 30\% sodium hydroxide aqueous solution to adjust the $\mathrm{pH}$ to about 5-7;

(5) Make up water to $50 \%$ solids to obtain polycarboxylic acid water reducing agent mother liquor.

\subsection{Test and detection methods}

The concrete test is carried out in accordance with the relevant provisions of GB 8076-2008 "Concrete Admixtures". Mainly test the performance indicators of C80 concrete slump, strength, air content, bucket down time, etc, under the same content of different water reducer samples; performance indicators such as strength, gas content, and pour time of the same water reducing agent under gradient blending conditions. The concrete mix ratio is shown in Table 1 . The amount of admixture is calculated based on the amount of solids.

Table 1. Concrete raw materials and mix ratio

\begin{tabular}{ccccccc}
\hline $\begin{array}{c}\text { Material } \\
\text { variety }\end{array}$ & $\begin{array}{c}\text { Cement/ } \\
\mathrm{C}\end{array}$ & Fly ash/Fa & $\begin{array}{c}\text { River sand/S } \\
(\mathrm{Mx}=2.3 \sim 3.0)\end{array}$ & $\begin{array}{c}\text { Gravel/G1 } \\
(5 \sim 16 \mathrm{~mm})\end{array}$ & $\begin{array}{c}\text { Gravel/G2 } \\
(5 \sim 31.5 \mathrm{~mm})\end{array}$ & $\begin{array}{c}\text { Tap } \\
\text { water/W }\end{array}$ \\
\hline $\begin{array}{c}\text { Mix ratio } \\
\left(\mathrm{kg} / \mathrm{m}^{3}\right)\end{array}$ & 460 & 140 & 620 & 400 & 730 & 155 \\
\hline
\end{tabular}

\section{Test results and discussion}

\subsection{Concrete performance test}

Experiments were performed on the properties of concrete with polycarboxylic acid water-reducing agents PCE1, PCE2, PCE3, and PCE4 synthesized with different molecular weight macromonomers in this experiment. The results are shown in Table 2; the line chart of the relationship between four different water reduction and bucket down time at the same dosage is shown in Figure1; the performance test results of the water reducing agent PCE1 synthesized with 1200 molecular weight macromonomer under the gradient content are shown in Table 3; Figure 2 shows the barrel reversal time line of PCE1 under the gradient content.

Table 2. Concrete test results

\begin{tabular}{|c|c|c|c|c|c|c|c|}
\hline \multirow{2}{*}{$\begin{array}{c}\text { Water } \\
\text { reducing agent } \\
\text { model }\end{array}$} & \multirow{2}{*}{$\begin{array}{l}\text { Amount of water } \\
\text { reducing agent } \\
(\%)\end{array}$} & \multicolumn{2}{|c|}{ Spread / Slump (mm) } & \multirow{2}{*}{$\begin{array}{l}\text { Air content in } \\
\text { concrete }(\mathrm{A} / \%)\end{array}$} & \multicolumn{2}{|c|}{$\begin{array}{l}\text { Strength } \\
(\mathrm{MPa})\end{array}$} & \multirow{2}{*}{$\begin{array}{l}\text { Bucket } \\
\text { time }(\mathrm{S})\end{array}$} \\
\hline & & Oh & $0.5 \mathrm{~h}$ & & $7 d$ & $28 \mathrm{~d}$ & \\
\hline PCE1 & 0.22 & $575 / 230$ & $570 / 220$ & 1.5 & 81.8 & 95.6 & 7 \\
\hline PCE2 & 0.22 & $600 / 240$ & $580 / 230$ & 1.0 & 83.2 & 97.6 & 12 \\
\hline PCE3 & 0.22 & $585 / 225$ & $585 / 230$ & 0.9 & 83.9 & 98.2 & 17 \\
\hline PCE4 & 0.22 & $570 / 225$ & $600 / 235$ & 0.7 & 83.4 & 96.8 & 18 \\
\hline
\end{tabular}

As can be seen from Table 2, when the content is the same, the gas content of PCE1, PCE2, PCE3, and PCE4 decreases once, indicating that as the molecular weight of polycarboxylic acid increases, the gas content of the polycarboxylic acid water reducing agent itself decreases Small trend; the slump loss of the concrete becomes smaller, and the strength of the concrete is equivalent at $7 \mathrm{~d}$ and $28 \mathrm{~d}$, which indicates that with the increase of the molecular weight of polycarboxylic acid, the ability of the water reducing agent to maintain the slump of the concrete increases, and it has little effect on the concrete strength; the time for the concrete to be poured down gradually becomes longer, which means that as the molecular weight of the polycarboxylic acid increases, the viscosity of the concrete mixed with the water reducing agent becomes larger, and the viscosity reducing effect becomes worse. Small-molecular-weight polycarboxylic acid water-reducing agent has obvious advantages over high-molecular-weight water-reducing agent in high-grade concrete, which is conducive to the pumping of concrete. 


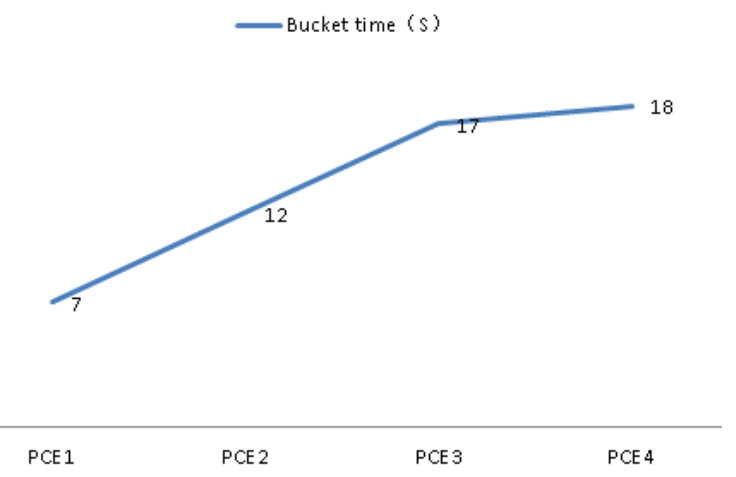

Figure 1. Line chart of the relationship between different water reducing agents and bucket down time

It can be seen from Figure 1 that with the increase of molecular weight of the four kinds of PCE1, PCE2,
PCE3, and PCE4, the pour-down time is rapidly extended. It can be seen that the molecular weight of polycarboxylic acid superplasticizer has a greater effect on the viscosity of concrete , Small molecular weight water reducing agent has obvious viscosity reducing effect; but when the molecular weight of the water reducing agent reaches a certain range, as the molecular weight of the water reducing agent increases, the viscosity reducing effect on the concrete gradually decreases; based on this result, the author believes that the small molecular weight polycarboxylic acid water reducing agent has a good viscosity reduction effect on concrete, and also provides theoretical guidance and data support for admixture production and development companies to solve such problems as excessive viscosity of high-grade concrete.

Table 3. Concrete test results

\begin{tabular}{|c|c|c|c|c|c|c|c|}
\hline \multirow{2}{*}{$\begin{array}{l}\text { Water reducing } \\
\text { agent model }\end{array}$} & \multirow{2}{*}{$\begin{array}{l}\text { Amount of water } \\
\text { reducing agent }(\%)\end{array}$} & \multicolumn{2}{|c|}{ Spread / Slump ( mm) } & \multirow{2}{*}{$\begin{array}{c}\text { Air content in } \\
\text { concrete }(\mathrm{A} / \%)\end{array}$} & \multicolumn{2}{|c|}{$\begin{array}{l}\text { Strength } \\
(\mathrm{MPa})\end{array}$} & \multirow{2}{*}{$\begin{array}{l}\text { Bucket } \\
\text { time }(\mathrm{S})\end{array}$} \\
\hline & & $0 \mathrm{~h}$ & $0.5 \mathrm{~h}$ & & $7 d$ & $28 \mathrm{~d}$ & \\
\hline \multirow{5}{*}{ PCE1 } & 0.22 & $575 / 230$ & $570 / 220$ & 1.5 & 81.8 & 95.6 & 7 \\
\hline & 0.24 & $595 / 235$ & $580 / 225$ & 1.8 & 82.0 & 94.2 & 5 \\
\hline & 0.26 & $625 / 240$ & $610 / 240$ & 2.2 & 80.2 & 92.0 & 8 \\
\hline & 0.28 & $630 / 240$ & $625 / 235$ & 2.3 & 80.1 & 90.8 & 12 \\
\hline & 0.30 & $640 / 245$ & $630 / 230$ & 1.6 & 83.8 & 95.8 & 20 \\
\hline
\end{tabular}

As can be seen from Table 3, with the increasing content of PCE1 in a certain range of polycarboxylic acid water reducer, the concrete slump first increases and then stabilizes, and the air content tends to increase first and then decrease, the bucket pour time decreases first and then increases, but with the increase of the amount of water reducing agent, the bucket pour time increases; the main reason is that the content is too high and the concrete homogeneity is poor; the strength of the concrete tends to be stable within the national standard range. PCE1 low-molecular-weight polycarboxylic acid water reducing agent has a significant viscosity reduction effect on ready-mixed concrete within a certain amount of range, and does not affect the strength of the concrete, it is beneficial to reduce the viscosity of high-grade concrete and promote better pumping of high-grade concrete and construction.

Amount of water reducingagent $(\%) \quad$ Bucket time (s)
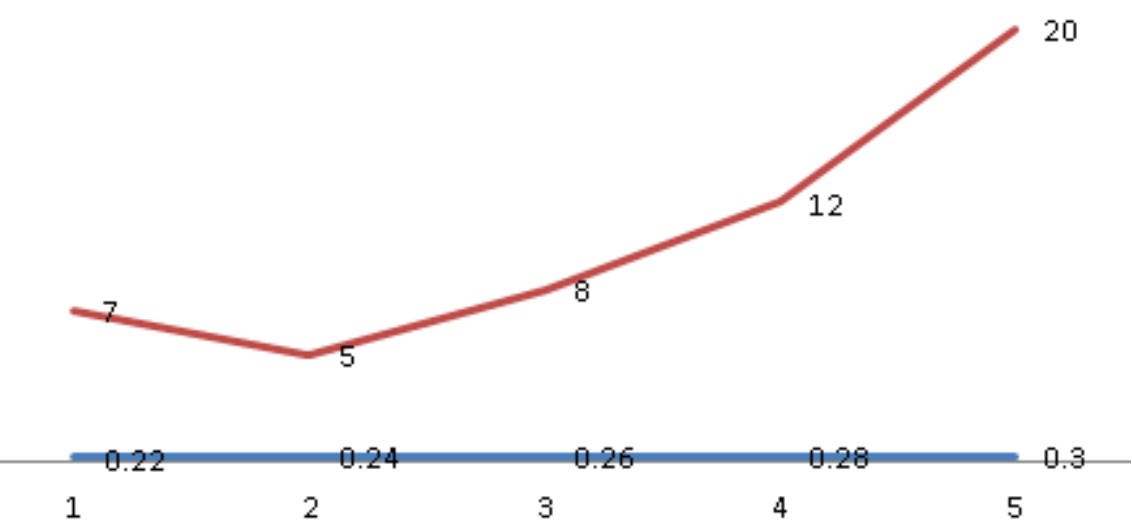

Figure 2. Line chart of the relationship between mixing amount and bucket down time

It can be seen from Figure 2 that with the increase of the PCE1 content, the concrete pail bucket time decreases first and then increases; the trend of the bucket down time of concrete is mainly due to the increase in the amount of PCE1, when the fluidity of the concrete soil reaches the highest value, the viscosity of the 
concrete is the lowest; then, with the increase of PCE1 content, the slump of the concrete further increased, the homogeneity of the concrete decreased, and the phenomenon of delamination and even bleeding occurred, which led to a longer pour time of the concrete. Therefore, when the amount of water reducing agent PCE1 reaches the peak of the concrete slump, the concrete has the best homogeneity, the lowest viscosity, the shortest bucket down time, and it is more conducive to pumping.

\subsection{Analysis of mother liquor performance and water reduction mechanism}

(1) Through the concrete tests of 4.1 and 4.2 , it can be seen that the polycarboxylate water reducers PCE1, PCE2, PCE3, and PCE4 of different molecular weights synthesized in this test have different viscosity reduction effects in high-grade concrete, the lower the molecular weight, the better the viscosity reduction effect ; the 1200 molecular weight macromonomer and synthetic polycarboxylic acid water reducing agent have the best viscosity reduction effect, and the water reduction rate is moderate, which does not affect the early and late strength of the concrete.

(2) Polycarboxylic acid superplasticizers with different molecular weights have different water reduction rates, air contents, and effects on concrete homogeneity and viscosity, polycarboxylic acid superplasticizers with low molecular weight perform well in high-grade concrete, the high molecular weight polycarboxylic acid water reducer is better in slump retention ability in concrete. In this experiment, a polycarboxylic acid water reducing agent synthesized with a 1200 molecular weight macromonomer has a short molecular structure side chain, so the steric hindrance effect of the water reducing agent is not obvious, which further reduces the sensitivity of the water reducing agent; at the same time, due to the reduction of the molecular weight of the side chain, the overall molecular weight of the water reducing agent is reduced, which is more conducive to the swimming and adsorption of the polycarboxylic acid water reducing agent in the cement slurry, and has a certain viscosity reducing effect; as the molecular chain of the side chain becomes shorter, the hydrating film wrapped on the surface of the cement particles becomes thinner, making the concrete softer and easier to pump. Therefore, the water reducing agent PCE1 synthesized in this experiment has the shortest pouring time of the concrete.

\section{Conclusion}

In summary, the following conclusions can be drawn:

(1) Polycarboxylic acid water reducer synthesized with low molecular weight macromonomers, due to the short side chains, the overall molecular weight of the polycarboxylic acid water reducer is low, it has a good viscosity reduction effect in high-grade concrete, which is conducive to pumping construction of concrete, it solves the problem of difficult pumping of high-grade concrete and has a more positive effect on the development of domestic water reducing agents;

(2) Different molecular weight macromonomers and synthetic polycarboxylic acid superplasticizers have different water reduction rates, the larger the molecular weight, the better the superplasticizer's ability to maintain the slump of the concrete, the worse the viscosity reduction effect in high-grade concrete; conversely, the lower the molecular weight, the higher the gas content of the water reducer, and the better the viscosity reduction effect in high-grade concrete. This test synthesizes short-chain branched polycarboxylic acid water reducer, which solves the problem of difficult pumping of high-grade concrete, fills the blank of domestic special additives for high-grade concrete, and has a more positive effect on the development of domestic water reducers.

\section{References:}

1. Development course and research and development direction of polycarboxylic acid water reducing agent [J]. Wang Ling, Gao Ruijun. Concrete World. 2012 (11).

2. Principle and Application of Concrete Admixtures [M]. China Planning Press, Edited by Chen Jiankui, 1997.

3. Effects of Polycarboxylate Water Reducers with Different Carboxy Densities on Properties of Cement Paste [J]. He Yan, Kong Yaning, Wang Xiaofu, Shui Liangliang. Journal of Building Materials. 2018 (02)

4. Plank J, Pöllmann K, Zouaoui N. Synthesis and performance of methacrylic ester based polycarboxylate superplasticizers possessing hydroxy terminated poly (ethylene glycol) sidechains[J]. Cement and Concrete Research, 2008, (38): 1210-1216. 